\title{
Social and Economic Factors of the Risk of Development of Russia's Human and Intellectual Potential
}

\author{
Larisa Selezneva \\ Financial University under the Government of the Russian Federation \\ Moscow, Russia \\ E-mail: 1selezneva@fa.ru
}

\begin{abstract}
The paper analyzes the socio-economic risk factors of the development of human and intellectual potential in modern Russia. The theoretical approaches of scientists, studying the relationship between economic growth, social conditions and the development of human and intellectual potential, draw attention to the fact that formation and development of the human and intellectual capital of the modern society is impossible without a positive demographic development, including the population growth, improving the quality of life and the reproduction of the population, the features of the demographic risk. The relevance of the topic of the scientific paper is due to the fact that one of the polemical problems requiring investigation is the relationship between the economic growth, social conditions and the development of human and intellectual potential. The paper reviews the relationship between the features of human development and the intellectual potential of modern society and the demographic situation in the country. In the process of studying the problem of the influence of socio-economic factors on possible risks for human development, the systematic and dialectical analysis was used. The features of the demographic situation in the country, which affect the development of human potential and intellectual potential, are revealed. The field of application of the results of the study is quite wide, as it makes it possible to continue researching the features of the problem indicated in the paper. Conducting effective socioeconomic and demographic policy in the country will create conditions for the development of human and intellectual potential.
\end{abstract}

Keywords-socio-economic factors; human capital and potential; intellectual potential; demographic risks; population reproduction

\section{INTRODUCTION}

The demographic situation forming in contemporary Russia is one of the problems requiring investigation of interrelations between economic growth, social conditions and development of human and intellectual potential. The attempt to solve the following problems is taken in this paper in order to achieve the set goal of the research:

- To identify factors and risks affecting formation and development of human and intellectual potential;
- To perform a theoretical analysis of the state of human potential and the demographic situation, to highlight accumulated social problems restraining development of the human resources.

Social and economic development is the process of increasing the capabilities for human development and human choices. Here economic growth is an important tool for human development, but not the final goal. Human development implies that people are obliged to influence the processes shaping their lives. It is essential to bridge retardation in various areas of human development, but it is no less important to provide the same and even broader opportunities for the future generations [1].

\section{PERFORMANCE}

The social development models with the above mentioned emphasis on economic growth and methods of its acceleration have been prevailing for a long period of time. However, it turned out that the formula "economic growth" = "human potential development" did not prove its value to the full extent and translated into increasing social and political instability and poverty of the population; thus the human potential development concept with the main aim to meet the people's needs and to materialize their ambitions became the most significant. The HDI (Human Development Index) concept elaborated by the experts of UNDP (United Nations Development Program), an international organization, in the last decade of the $20^{\text {th }}$ century suggests that not only GDP (Gross domestic product, a macroeconomic parameter reflecting the market value of all end products and services (i.e. intended to be used directly) produced in all sectors of economy within the territory of a state over a year for consumption, export and accumulation regardless of the national origin of the inputs), but also the parameters characterizing health, education and access to information should be considered as the main indicators.

The HDI concept contains the fundamentals of the human potential development: increasing life duration, decreasing burden of disease together with adequate and affordable medical services; personal security; growing opportunities for education and educational level of the 
population; equal rights for social support and availability of social benefits; favorable environmental conditions with decreasing level of pollution; the opportunity to be employed for fair consideration; economic security of citizens, social groups and local communities.

In this paper, human potential development means the process of expanding the range of human capabilities in various fields of activity due to positive changes in physical, social, psychological and intellectual characteristics of people as well as social and economic conditions of the environment.

At present, intellectual features and intellectual potential of an individual and the society are becoming increasingly sought after in modern life - to the point that they determine the opportunities not only for development, but for the very existence and even survival. The significance of the intellectual potential lies in the fact that by enabling people to get high-quality education (particularly higher education) the society enhances both their and its own intellectual potential. It should be noted that the richer the intellectual potential of the society is, the more efficiently it will rise to the challenges it has to face [2].

Formation and development of the human and intellectual capital of the contemporary society is impossible without positive demographic development including both population growth and improvement of the population reproduction quality. It should be noted that according to forecasts of some specialists the countries with larger population size will be more competitive and developed.

At present, an extremely unfavorable situation with the reproduction of population has arisen in the Russian Federation; it can be characterized as a prolonged demographic crisis leading to irreversible negative demographic effects and social and economic risks.

Demographic risks are risks related to degradation of the demographic situation. Experts say that the demographic situation in Russia is characterized by decrease of the population size, low birth rates and wide prevalence of families with few children failing to provide reproduction of population.

Experts forecast a decline in population that will inevitably gather pace rapidly and may approximate 400,000 people by 2035 even by the most optimistic forecast; in the worst-case scenario, it may reach $1,000,000$ people. According to the intermediate forecast scenario of the NRU HSE Institute of Demography, the population of Russia will reduce to 142.3 million of people by 2050 [3].

Demographic ageing of the population is going on. It is characterized by extremely high level of premature mortality and low life duration of the population.

It is stated in the report that "our country is entering the period of very unfavorable changes in the age structure of the population. Unprecedented reduction in the number of potential mothers is among the consequences of these changes. This reduction will continue in the nearest 15 years, and the number of women in the most important maternal ages of 20-40 years will decrease by 7-8 million (i.e. by one third approximately) in the early 2030-ies as compared with the peak of 2010-2012".

The term "demographic potential of a country or a region" means the population with certain qualitative characteristics necessary for social and economic development of this territory.

The demographic potential has characteristics relating it to social and economic development. First of all, the size and quality of labor resources and, consequently, functioning of the economy will depend directly on the quantity, structure and quality of the demographic potential. In the second place, efficient development of social and economic systems (economy models) may be judged by the quality of the demographic potential. Social and economic systems function more successfully in the countries where people are mostly well-to-do, healthy, have access to education, high rates of life duration, standard and quality.

Russian specialists including economists continuously investigate impacts of demographic factors on the economy [4]. In particular, the number of employable citizens in Russia is decreasing and the demographic burden on them is growing. Furthermore, employable population is getting older. In the early 1960-ies the age group of 20-39 accounted for approximately $60 \%$ of the total population in the age of 20-64 creating favorable conditions for fast refreshment of labor forces due to inflow of younger manpower. In 2015 this proportion reduced to $47 \%$. It will continue decreasing until it comes down to $36-38 \%$ in the early 2030 -ies. Changes in the population size with constant labor activity parameters will result in reduction of the economically active population size by $16-20$ million people within the nearest twenty years.

The current changes in the population age structure are very important from the viewpoint of economic policy. The number of youth in the Russian Federation decreased by almost 3 million people within the period from 2010 to 2014 (more than 36 million in 2010, more than 34 million in 2014). According to forecasts the total number of youth may reduce to 25 million people by 2025 .

Reduction in the number of young people in Russia will lead to increased disproportion in the formation of labor resources and decrease in the amount of skilled personnel trained in educational institutions.

At present the youth of the RF accounts for $27 \%$ of the total population size in the country, 22.3 million of young people are employed in the national economy. But the proportion of youth among the people employed in the national economy, especially in industry, construction and transportation is constantly decreasing. The percentage of youth in the non-production sphere is growing due to structural changes in the economy. And this requires modifications of their training and retraining structure.

The dependency ratio was calculated. The forecast up to 2031 demonstrates that the dependency ratio will increase in any scenario. The number of people in the employable age will decrease every year. Perhaps many factors such as birth 
rate, mortality, healthcare problems, etc. will affect this process.

The demographic potential is characterized by quantitative and qualitative parameters used as criteria for its assessment.

Demographic ageing because of the demographic transition takes place in all countries including Russia but in Russia it was suspended several times for a short period, when the generations born in the first half of the $20^{\text {th }}$ century difficult for the country reached the older ages.

The age-related changes in the population composition embrace all main sectors of the economic field: the labor market, the consumer market, the services market and the savings market; they affect the investment environment, the social expenditures and consequently the taxation system and tax amounts and the financial flows.

In accordance with the international criteria, the population is considered old in case the proportion of people in the age of 65 and more exceeds $7 \%$ of the total population. At present almost every eighth Russian (i.e. $12.9 \%$ of the country inhabitants) is in the age of 65 and more.

The features of the demographic situation in the country, which affect the development of human potential and intellectual potential, are revealed [5]. The field of application of the results of the study is quite wide, as it makes it possible to continue researching the features of the problem indicated in the article.

Demographic potential creates basic, basic conditions for the reproduction of the population, both in favorable years, and in hard times. For example, the" adult component "of demographic potential as a result of German-fascist aggression decreased by about 25 million people (about 17 million men and 8 million women died), and the "child component" - by 3 million people (mainly due to a decrease in fertility). If we accept that before the great Patriotic war the population of the age of 55-60 years was about 145-150 million man, the demographic potential of the country (mainly about $80 \%$ provided by the Russian, Eastern Slavic ethnos) was damaged, equal to almost $20 \%$ of its initial value $(28: 150=0.19)$. In our opinion, this damage or the large deficit of demographic potential created by the war is one of the essential reasons of acceleration of the demographic crisis which has struck Russia in the 90th years of the last century and nowadays deepening [6].

It should be noted that the state needs a balanced programme for the development of social infrastructure both at the Federal, regional and local levels. At the moment, describing the socio-economic development, it is impossible to limit only the number of institutions and facilities that create conditions for the most effective activities of citizens, falls on a particular territory, the region. It is necessary to know how many material elements account for one or ten thousand people of the population of the country to compare the received data with normative requirements. Regulations relating to social infrastructure, should rely on developed in the previous period terms, as well as their individual assessment. It is also necessary to rely on the experience and statistical data of the set of existing objects of regulation and by calculation, determined on the basis of the analysis of scientific information and data.

\section{CONCLUSION}

It is necessary to consider ageing of the Russian population in implementation of the national demographic policy. Many social systems and institutions that have formed under the conditions of the previous age structure (healthcare, education, social security, the consumer market) must reform with due regard for the new demographic realities.

Solution of the demographic issues must among others become top-priority for the state as the forecasts show that our country will face not only economic and social, but even more global problems unless efficient measures are taken.

Conducting effective socio-economic and demographic policy in the country will create conditions for the development of human and intellectual potential.

\section{REFERENCES}

[1] Boris Yudin, Intellectual potential of personality // Electronic publication: Center for Humanitarian Technologies. 26.10.2010. URL http://gtmarket.ru/laboratory/expertize/3523.

[2] V.V. Kayukov, Yu.L. Melchakova, Interrelation of demographic processes with the state of the economy // Economics, management, finance: materials III Intern. sci. Conf. (Perm, February 2014). Perm: Mercury, 2014, pp. 177-180.

[3] Human Development Report 2016. Human Development for All and Everyone. The United Nations Development Program (UNDP), http://hdr.undp.org/sites/default/files/HDR2016_EN_.

[4] P.V. Povetiev, Human potential of the Russian Federation: Demographic aspect / P.V. Povetiev. M.: NIRSI, 2009.

[5] A. Kudrin, E. Gurvich, Aging of the population and the threat of a budget crisis. Global demographic. Issues of Economics, 2012, No. 3, pp. 52-79.

[6] R.E. Kovalev, Methodological aspects of projecting the population in a globalizing economy // Nauka-rastudent.ru, 2016, No. 01 (25) / [Electronic resource]. - URL: http://nauka-rastudent.ru/25/3165/. 